\title{
Influence of chemistry and runout table parameters on hot coil collapse in C-Mn steels.
}

\author{
by \\ Kevin Banks ${ }^{+}$, Alison Tuling ${ }^{+}$and Barrie Mintz* \\ + IMMRI, University of Pretoria \\ ${ }^{*}$ City University, London
}

\begin{abstract}
The key metallurgical parameters affecting the incidence of coil collapse (soft slump) of C-Mn steels has been investigated using industrial data and laboratory simulation. Runout table (ROT) cooling/coiling simulations were performed on a Gleeble 1500D to study transformation before and during coiling of thin strip. For low $C(<0.07 \%)$ grades, coiling temperatures above $650^{\circ} \mathrm{C}$ coupled with high nitrogen contents decreased the transformation-end temperature, $\mathrm{Ar}_{1}$, and increased collapse. Coiling temperatures above the $\mathrm{Ar}_{1}$ for ROT cooling increased both dilation and the time to complete transformation during coiling. These effects correlated with industrial conditions where a high frequency of coil collapse was observed.
\end{abstract}

\section{Introduction}

For ease of storage and transport, steel strip is commonly produced in the form of coil. Incorrect tension application after hot rolling can lead to stress/strain instabilities during coiling and result in collapse. One form of coil collapse is known as "soft slump". In this case the coil cannot hold up under its own mass to retain its cylindrical form and, as such, presents difficulties when fitting onto a mandrel to unwind the coil.

Research work to date $[1,2,3,4]$ on the problem of "soft slump" has concentrated on coil tension but it is not proposed to deal with it here. The present paper is mainly concerned with the influence of transformation of austenite on the occurrence of coil collapse in thin strip. The reported incidence of coil collapse in thin (1.6-3mm) low $\mathrm{C}$ coils is examined and related to the composition, in particular the $\mathrm{N}$ and $\mathrm{C}$ contents and steel processing route. Analysis of this industrial data indicated that the austenite-ferrite/pearlite transformation may be one of the important factors controlling the incidence of coil collapse. Dilatometer studies were therefore carried out to determine the transformation characteristics of these steels under runout table (ROT) cooling and coiling conditions.

\section{Industrial Data Analysis}

The composition range of low $\mathrm{C}$ industrial strip steel data that was analysed is given in Table I. 
Table I Analysis of commercial grades.

\begin{tabular}{|c|c|c|c|c|c|}
\hline Grade & C, \% & Mn, \% & S, \% & Al, \% & N,ppm \\
\hline AI & $0.02-0.07$ & $0.17-0.29$ & $<0.015$ & $0.02-0.06$ & $15-110$ \\
\hline AII & 0.03 & 0.25 & $n a$ & $n a$ & 47 \\
\hline
\end{tabular}

Fig. 1 shows the incidence of coil collpase in low $\mathrm{C}$ grade $\mathrm{AI}$ and low $\mathrm{C}-\mathrm{B}$ gradeAII as a function of total N content. Grade AI was produced via both EAF (high N) and BOF (low N) steelmaking routes and showed a bi-modal nitrogen distribution. Grade AII was only produced at BOF. In grade AI, fig.1a, a significant increase in the incidence of coil collapse occurred in the high $\mathrm{N}$ steels produced at EAF. There were no coil collapses in grade AII, fig.1b and this was attributed to i)low $\mathrm{N}$ content and ii)precipitation of $\mathrm{BN}$ during rolling, which negated any detrimental effect solute nitrogen may have had during coiling.

(a) Grade Al (EAF \& BOF):

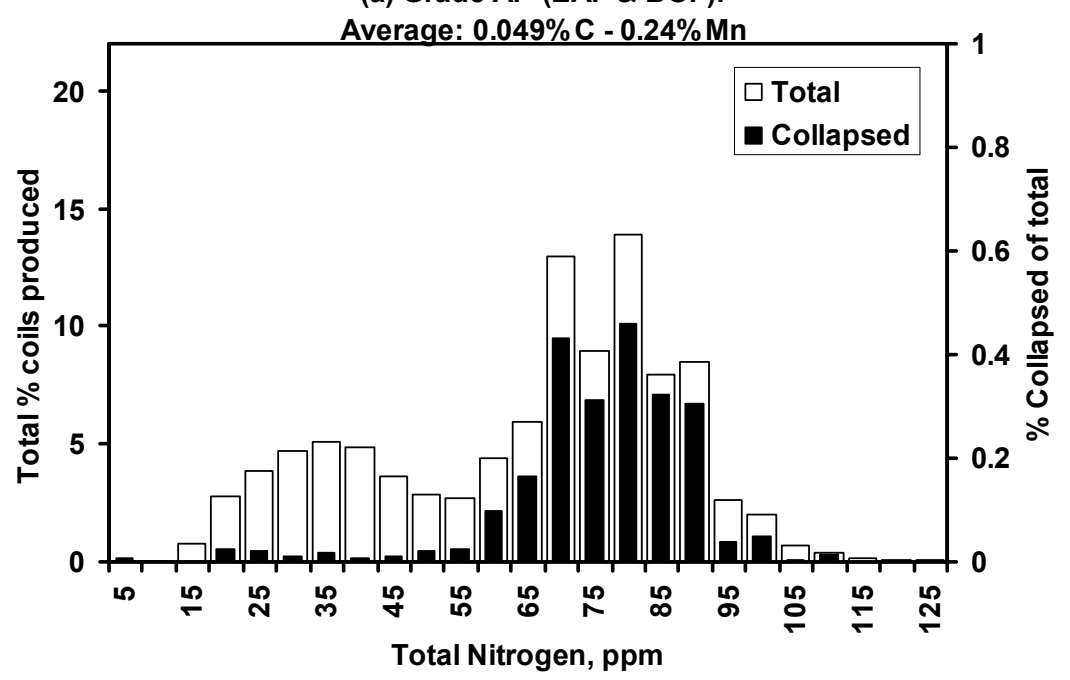

(b) Grade All (BOF only):

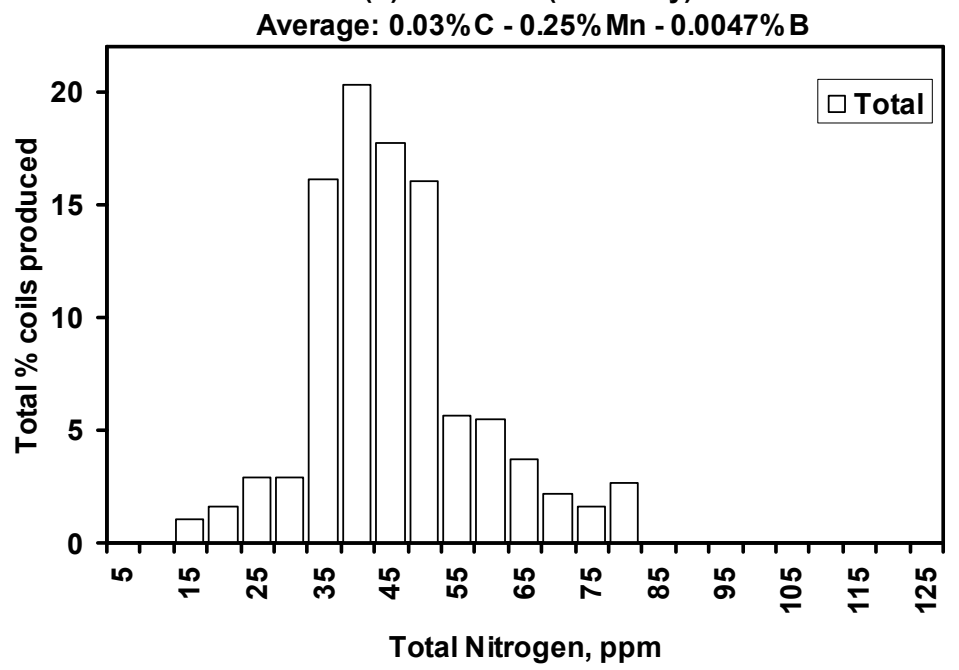

Figure 1. Influence of $\mathbf{N}$ content on coil collapse in low $\mathrm{C}$ steels $\mathrm{Al}$ and All Higher $\mathrm{N}$ contents in steel Al produced at EAF increased the incidence of coil collapse. Average composition shown. 
If transformation during coiling is a key factor in determining whether coil collapse occurred then there should be a correlation between the incidence of coil collapse and the coiling temperature.

Fig.2a shows the percentage of coils collapsed against the average coiling temperature for grade A 1 over a period of four years. EAF material is prone to collapse most frequently at coiling temperatures above $650^{\circ} \mathrm{C}$. Collapsing of low $\mathrm{N}(\mathrm{BOF})$ steel is not as sensitive to coiling temperature and reached a maximum of about $2 \%$ at $675^{\circ} \mathrm{C}$. The combined influence of coiling temperature and total $\mathrm{N}$ content is shown clearly in fig. $2 \mathrm{~b}$. For coiling temperatures below $650^{\circ} \mathrm{C}$, the number of coils collapses was restricted to below $1 \%$, irrespective of $\mathrm{N}$ content. However, above $650{ }^{\circ} \mathrm{C}$, the annual collapses increased from about $2 \%$ for coils with $30-50 \mathrm{ppm} \mathrm{N}$ to $\sim 6-14 \%$ for coils with $\mathrm{N}$ contents of 70-90ppm. A simple solution is to restrict the $\mathrm{N}$ content to less than $50 \mathrm{ppm}$ and/or coil below $650^{\circ} \mathrm{C}$. This, however, is not always practical, particularly if capacity at the $\mathrm{BOF}$ is limited or if high coiling temperatures are required to achieve specific microstructures.

(a)

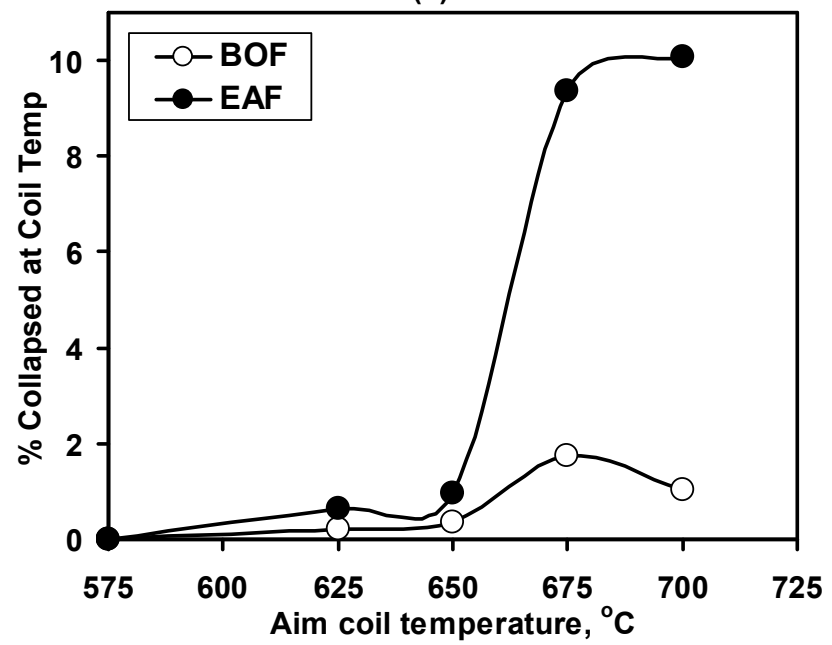

(b)

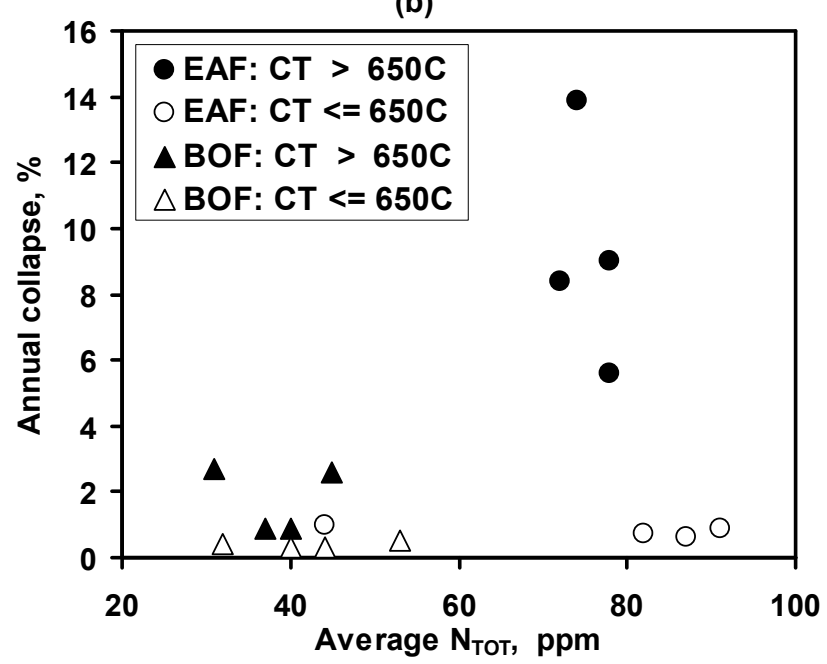

Figure 2. Grade Al: Influence of (a) average target coiling temperature over four years and (b) average total [N] content on coil collapse (each point in (b) represents the average of one year).

\section{Estimated transformation end temperatures}

EAF steels generally have lower transformation-end, $\mathrm{Ar}_{1}$, temperatures due to their higher $\mathrm{C}$ and $\mathrm{Mn}$ contents. Equation 1 was used to calculate the average $\mathrm{Ar}_{1}$ temperature as a function of $\mathrm{C}$ and $\mathrm{Mn}$ only[7], i.e. cooling rate is not varied. Equations for $\mathrm{Ar}_{1}$ are extremely scarce and are, at best, formulated for constant cooling rates.

$\mathrm{Ar}_{1}=706.4-350.4 \mathrm{C}-118.2 \mathrm{Mn}$ [ref. 7$]$

However, the cooling path during ROT cooling and subsequent coiling is complex, with the cooling rate frequently changing between the air, water, air and coiled conditions. The end of transformation in this work is a result of these changes in cooling rate. Fig.3 shows that, considering only $\mathrm{C}$ and $\mathrm{Mn}$ levels, BOF steels have on average, a predicted $\mathrm{Ar}_{1}$ temperature under constant cooling rate about $5^{\circ} \mathrm{C}$ higher than the average value of $665^{\circ} \mathrm{C}$ at EAF. This suggests that, for a given target coil temperature above $665^{\circ} \mathrm{C}, \mathrm{EAF}$ grades are slightly more prone to collapsing due to less transformation occurring on the ROT above the $\mathrm{Ar}_{1}$ temperature. Fig. 3 showed that, whilst the 
calculated $\mathrm{Ar}_{1}$ shows a normal distribution at EAF, it is continuous but skewed towards the left at BOF. In both steelmaking routes, almost all (>95\%) steels had a calculated $\mathrm{Ar}_{1}$ above $650^{\circ} \mathrm{C}$, which coincided with the data in fig. 2 , where $650^{\circ} \mathrm{C}$ was found to be the dividing line for high and low occurrences of coil collapse.

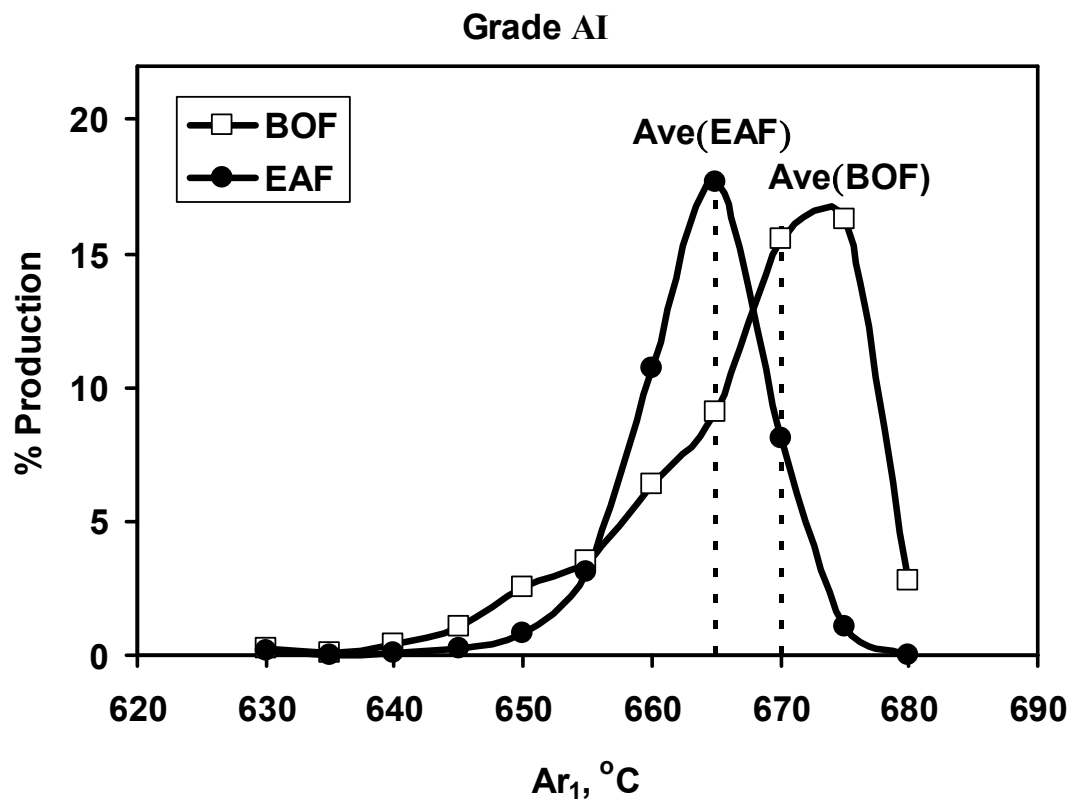

Figure 3: Calculated $\mathrm{Ar}_{1}$ temperature for $\mathrm{EAF}$ and $\mathrm{BOF}$ low $\mathrm{C}$ steel grade $\mathrm{A} 1$ using equation 1 [7]. $\mathrm{The}_{\mathrm{Ar}}$ is, on average, about $5^{\circ} \mathrm{C}$ lower in coils produced at EAF.

\section{Experimental}

Dilatometry was carried out on grade AI steels using a Gleeble 1500D thermomechanical simulator to determine whether coil collapse could be related to cooling conditions on the ROT and thus the austenite-to-ferrite/pearlite transformation. A number of steels with varying total nitrogen, $\mathrm{N}_{\text {TOT, }}$ and carbon levels were used, Table II. Boron treated steel AII was also included in the table, the addition of boron being expected to remove all the free $\mathrm{N}$ as boron nitride.

Table II Composition of strip steels investigated

\begin{tabular}{|c|c|c|c|c|c|c|c|}
\hline Grade & CID HSM & $\begin{array}{c}\mathrm{C} \\
\%\end{array}$ & $\begin{array}{c}\mathrm{Mn} \\
\%\end{array}$ & $\begin{array}{c}\mathrm{N}_{\text {TOT }} \\
\mathrm{ppm}\end{array}$ & $\begin{array}{c}\mathrm{Al} \\
\%\end{array}$ & $\begin{array}{c}\mathrm{S} \\
\%\end{array}$ & $\begin{array}{c}\mathrm{B} \\
\mathrm{ppm}\end{array}$ \\
\hline $\mathrm{AI}$ & 4090 & 0.046 & 0.22 & 14 & 0.044 & 0.015 & na \\
\hline AI & 9108 & 0.030 & 0.18 & 28 & 0.034 & 0.015 & na \\
\hline AI & 0038 & 0.040 & 0.18 & 28 & 0.039 & 0.013 & na \\
\hline AI & 8091 & 0.049 & 0.22 & 101 & 0.028 & 0.011 & na \\
\hline AI & 5021 & 0.069 & 0.20 & 52 & 0.052 & 0.009 & na \\
\hline AI & 9026 & 0.060 & 0.21 & 99 & 0.040 & 0.009 & na \\
\hline AII & AC7-33 & 0.03 & 0.25 & 40 & na & na & 47 \\
\hline B & AC5-31 & 0.100 & 0.45 & 50 & 0.040 & na & na \\
\hline C & AC5-34 & 0.160 & 0.75 & 50 & 0.040 & na & na \\
\hline D & AC5-37 & 0.160 & 1.00 & 50 & 0.040 & na & na \\
\hline
\end{tabular}


The $\mathrm{C}$ and $\mathrm{Mn}$ levels ranged between 0.03 to $0.07 \%$ and 0.18 to $0.22 \%$ respectively. The $\mathrm{N}$ level varied by an order of magnitude from 15 to $101 \mathrm{ppm}$. Al levels also covered a wide range from 0.028 to $0.052 \%$.

Strip specimens of dimensions $80(1) \times 5.5(w) \times 2-2.5(\mathrm{t}) \mathrm{mm}^{3}$ were subjected to simulated ROT cooling cycles typical for $2 \mathrm{~mm}$ strip, shown in figs. $4 \mathrm{a}$ and $4 \mathrm{~b}$ below. In previous research, specimens for transformation studies were either (i) heated to just above the $\mathrm{Ae}_{3}$ temperature followed by cooling or (ii) austenitised at typical reheat furnace temperatures followed by deformation and cooling. It is the free $\mathrm{N}$ content, [N], rather than the total $\mathrm{N}$ that influences transformation. However, in order to study the effect of solute $\mathrm{N}$ on transformation, specimens had to be soaked at a sufficiently high temperature $\left(1114-1200^{\circ} \mathrm{C}\right)$ to dissolve any nitrides present, in this case AIN. This was unfortunately at the expense of commencing the ROT cooling simulation with a fairly large austenite grain size, which lowers the transformation temperature. To minimise this, the soak time was restricted to $2 \mathrm{~min}$. After soaking, specimens were cooled to the simulated last finish rolling stand, F7 temperature of $890^{\circ} \mathrm{C}$ and cooled at a typical water cooling rate for 2 mm thick strip, $\sim 100 \mathrm{~K} / \mathrm{s}$.

Thereafter, the specimen was subjected to an air cooling rate of about $12 \mathrm{~K} / \mathrm{s}$ until the simulated coiling temperature between 725 and $575^{\circ} \mathrm{C}$ was reached, where the specimen was cooled $10 \mathrm{~K}$ over a period of 1-2min to simulate slow cooling in the coil, fig.4a. The dilation was recorded across the specimen width during the test. Similar dilatometry tests were also carried out on higher carbon $(0.1-0.16 \%)$ steels B, C and D.

The $[\mathrm{N}]$ content corresponding to each soak temperature, $\mathrm{Al}$ and total $\mathrm{N}$ content was calculated from an expression developed by Sun et al [8] and is based on mass balances. Included in this equation is the Leslie et al [5] formula for AlN dissolution:

$$
[\mathrm{Al}]=\left(\frac{\mathrm{Al}_{\mathrm{TOT}}-\mathrm{N}_{\mathrm{TOT}}}{2}\right)+\left(\left[\frac{\mathrm{Al} \text { TOT }-\mathrm{N}_{\mathrm{TOT}}}{2}\right]^{2}+\exp \left(\left[1.03-\frac{6770}{\mathrm{~T}}\right] / 0.4343\right)\right)^{0.5}
$$

$[\mathrm{N}]=\frac{10^{1.03-6770 / \mathrm{T}}}{[\mathrm{Al}]}$

where $T$ is the soak temperature in $\mathrm{K}$ and composition is in mass- $\%$. Although deformation may accelerate precipitation during rolling, the formation of AIN is noted for being very sluggish [6]. It is thus reasonable to assume that the values quoted henceforth for the free $\mathrm{N}$ level are representative of $[\mathrm{N}]$ prior to cooling on the ROT.

It must be noted that the austenite grain size before the ROT is expected to be larger in the laboratory simulations than in the industrial condition where deformation refines the grains, which will also influence the transformation behaviour. 


\section{Results and Discussion}

$\underline{\mathrm{C}<0.07 \%}$

Influence of cooling path on transformation: Typical cooling paths for the simulated ROT cooling and coiling of a $2 \mathrm{~mm}$ strip are shown in fig.4a. After rolling in the austenite region, the air and accelerated water cooling on the ROT, results in strip contraction. Once the transformation from the fcc austenitic structure to the bcc ferritic phase starts, expansion of the strip takes place. When transformation is complete the strip again contracts due to the temperature decrease. Because of the complexity of the thermal path after rolling in austenite, completion of transformation can occur at various locations: i)on the ROT, ii)during the coiling process or iii)after coiling. This is further complicated by partial transformation during rolling at different strip locations, particularly the edges. Cooling is non-linear and another consideration is the exothermic re-calescence due to the latent heat of the pearlite transformation, which potentially reduces the subsequent cooling rate.

Fig.4a shows that in the time available from the end of finishing to the start of coiling, $\sim 11$ seconds, the coiling temperature controls the expansion/contraction behaviour during the coiling operation, fig $4 \mathrm{~b}$. In this figure, the maximum amount of dilation during coiling is defined as $\theta$ in $\mu \mathrm{m} / \mathrm{mm}$. To get an indication of the transformation kinetics for various chemistries and coiling conditions, the time to transformation-end from the start of coiling, $t_{\mathrm{e}}$, was determined at the point of maximum dilation.

At low coiling temperatures, in this case $575^{\circ} \mathrm{C}$, transformation is completed before the start of coiling, leading to either a nett contraction or no dimension change during coiling. Increasing the coiling temperature to $675^{\circ} \mathrm{C}$, results in most transformation occurring on the ROT but completion occurs during the early stages of coiling, as seen by the rapid dilation followed by quick (within $3 \mathrm{~s}$ ) leveling off of the expansion. Further raising the coiling temperature to $725^{\circ} \mathrm{C}$ intensifies the extent of transformation during coiling. Because the strip is in the early stages of transformation coincident with the upper region of the CCT curve, the dilation occurs at a slower rate than at $675^{\circ} \mathrm{C}$. If coiling took place at sufficiently high temperatures, there will be little or no dilation because the strip temperature is in the single austenite phase. Coiling before the onset of transformation is a strategy that is often used to successfully coil medium C steels. Similar dilation curves were observed in delayed ROT tests, not shown.

Slower rolling speeds associated with thick strip result in longer times on the ROT and hence, more time for transformation to go to completion. This is partially the reason why a higher fraction of collapses are found in thin strip coils.

Influence of $\boldsymbol{C}$ and $\boldsymbol{N}$ on transformation: In order to establish the influence of [N] on the transformation start temperature during cooling, the transformation trough temperature, $T_{\mathrm{s}}$, (approximate $\mathrm{Ar}_{3}$ under ROT cooling conditions) was plotted as a function of coil temperature for steels with similar $\mathrm{C}$ contents and soaking temperature, fig.5. It was assumed that the steels had similar austenite grain sizes at a given soak temperature. As expected, $T_{\mathrm{s}}$ decreases with decreasing coiling temperature because of increased undercooling, thereby increasing hardenability. For a soak temperatures of $1114^{\circ} \mathrm{C}$, fig. $5 \mathrm{a}$, the steel with higher $[\mathrm{N}]$ commenced transformation approximately $20^{\circ} \mathrm{C}$ lower than the low $[\mathrm{N}]$ steel. 

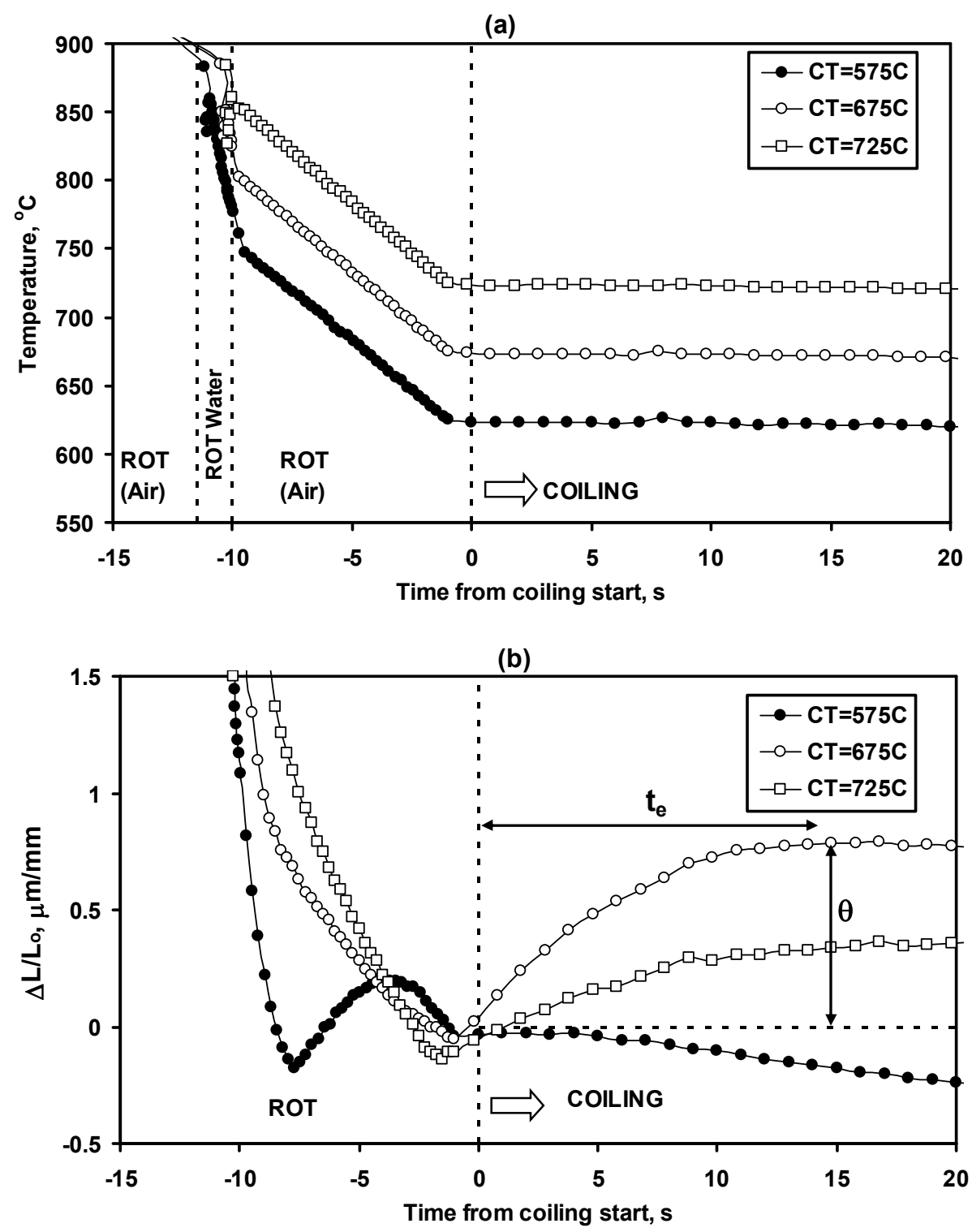

Figure 4 Gleeble simulations of conventional ROT cooling and coiling for $2 \mathrm{~mm}$ strip showing (a) temperature-time and (b) dilation-time. Steel 9026 (high N). Soaked at $1200^{\circ} \mathrm{C}$, accelerated cooled from simulated $\mathrm{F} 7$ temperature of $890^{\circ} \mathrm{C}$.

A similar result was found for a soak temperature of $1200^{\circ} \mathrm{C}$, fig. $5 \mathrm{~b}$. The actual mechanism for $\mathrm{N}$ lowering the transformation is not fully understood, but it has been suggested [9] that nitrogen may hinder nucleation or growth of the pearlite reaction by interfering with diffusional processes or that $\mathrm{N}$ rapidly partitions to the last transforming austenite, increasing hardenability. 

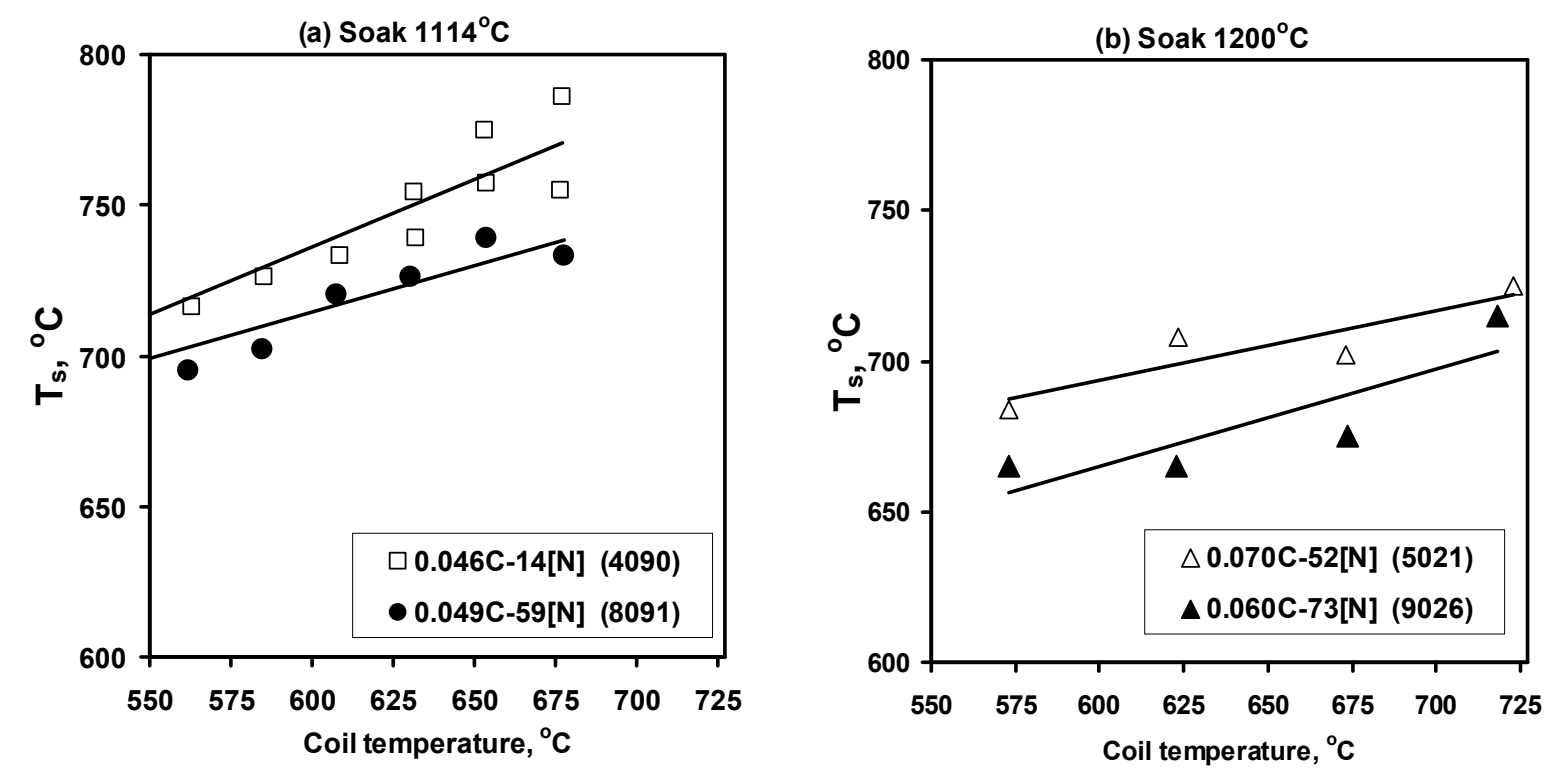

Figure 5. Gleeble simulations: Influence of free $\mathrm{N}$ on approximate $\mathrm{Ar}_{3}$ temperature (transformation start trough temperature, $\mathbf{T}_{\mathbf{s}}$ ) in low $\mathbf{C}$ steels under ROT cooling conditions. (a) $0.046-0.049 \% \mathrm{C}$ soaked at $1114^{\circ} \mathrm{C}$ and (b) $0.06-0.07 \% \mathrm{C}$ soaked at $1200^{\circ} \mathrm{C}$.

Dilation-temperature curves are shown in figs. 6a-c as a function of decreasing $[\mathrm{N}]$ for steels soaked at $1114^{\circ} \mathrm{C}$ and in figs.6d-f for steels soaked at $1200^{\circ} \mathrm{C}$. In these figures $L$ is the dilation in $\mu \mathrm{m}$ and $L_{0}$ is the initial specimen width in $\mathrm{mm}$. These figures have the following distinguishing features:

- Specimens experiencing complete transformation prior to coiling have a well-defined dilation trough and peak, indicating the temperature region where the bulk of the transformation occurs. A well-defined peak is usually followed by a nett contraction during simulated coiling.

- Specimens not displaying a distinct peak in dilation, experience a nett dilation during simulated coiling, indicating that the austenite transformation was not completed on the ROT.

For similar $\mathrm{C}$ and $\mathrm{Mn}$ contents, as the [N] content increases, the necessary coiling temperature to avoid dilation decreases. Comparison of figs. $6 \mathrm{a}-\mathrm{c}$ for a soak temperature of $1200^{\circ} \mathrm{C}$ shows the steel with a $[\mathrm{N}]$ content of $72 \mathrm{ppm}$ displays significant dilation at a coiling temperature of $675^{\circ} \mathrm{C}$, whilst that of the $28 \mathrm{ppm}[\mathrm{N}]$ steel only displayed dilation at a coiling temperature of $725^{\circ} \mathrm{C}$. Increasing the "safe" coiling temperature region with decreasing $[\mathrm{N}]$ was also found by comparing steels in fig.6d-f at a lower soak temperature of $1114^{\circ} \mathrm{C}$.

Fig.7 shows plots of $\theta$ and $t_{\mathrm{e}}$ during coiling for low $\mathrm{C}$ steels having various [N] contents. Clearly seen is that, above $650^{\circ} \mathrm{C}$, both $\theta$ and $t_{\mathrm{e}}$ increase with temperature, especially in the high [N] grades. This would imply that large dilations, coupled with long transformation-end times, present a highrisk condition for coil collapse. This is consistent with the argument that dilating strip towards the tail-end will interfere with the pinch roll tension settings on leaving the finishing mill. The $650^{\circ} \mathrm{C}$ "dividing line" was in good agreement with industrial observations, fig.2, and the approximate calculated $\mathrm{Ar}_{1}$ temperature for over $95 \%$ of all grade A steels, fig. 3 . 
9026: $0.06 \mathrm{C}-0.211 \mathrm{Mn} 72[\mathrm{~N}]$ Soak=1200C

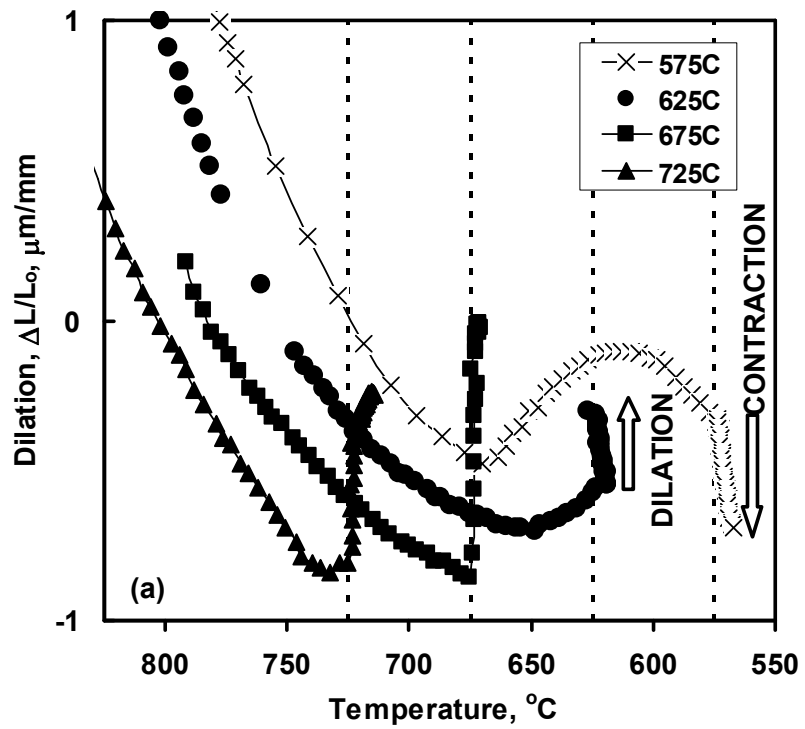

9108: $0.03 \mathrm{C}-0.183 \mathrm{Mn} 28[\mathrm{~N}]$ Soak=1200C

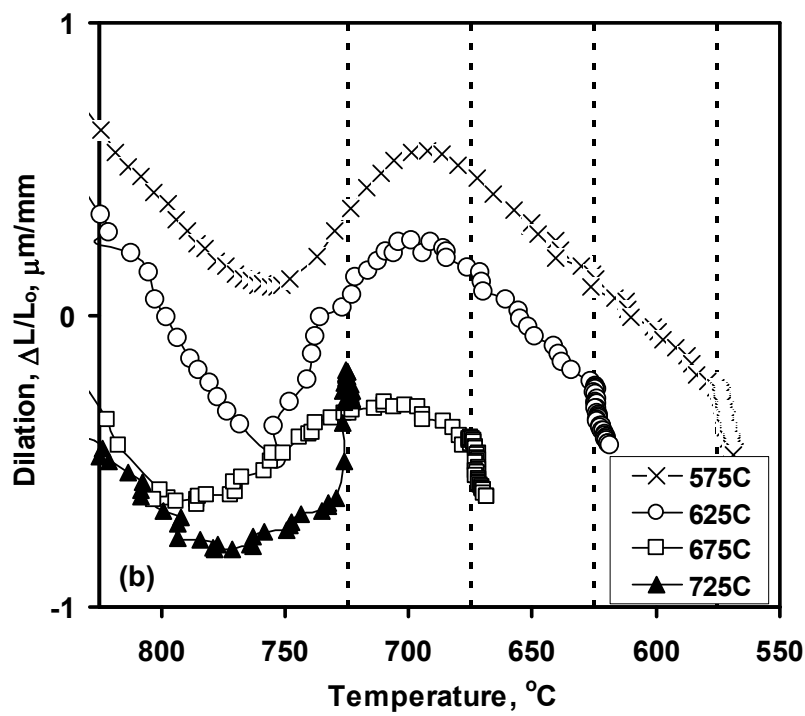

8091: 0.049C- 0.222Mn $59[\mathrm{~N}]$ Soak=1114C

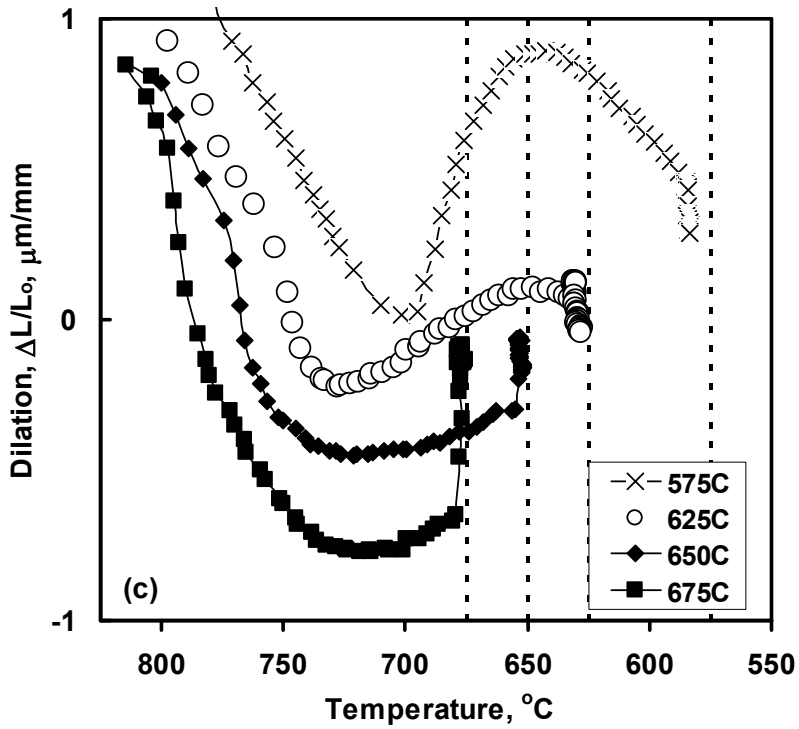

4090: 0.046C- 0.22Mn $14[\mathrm{~N}]$ Soak=1114C

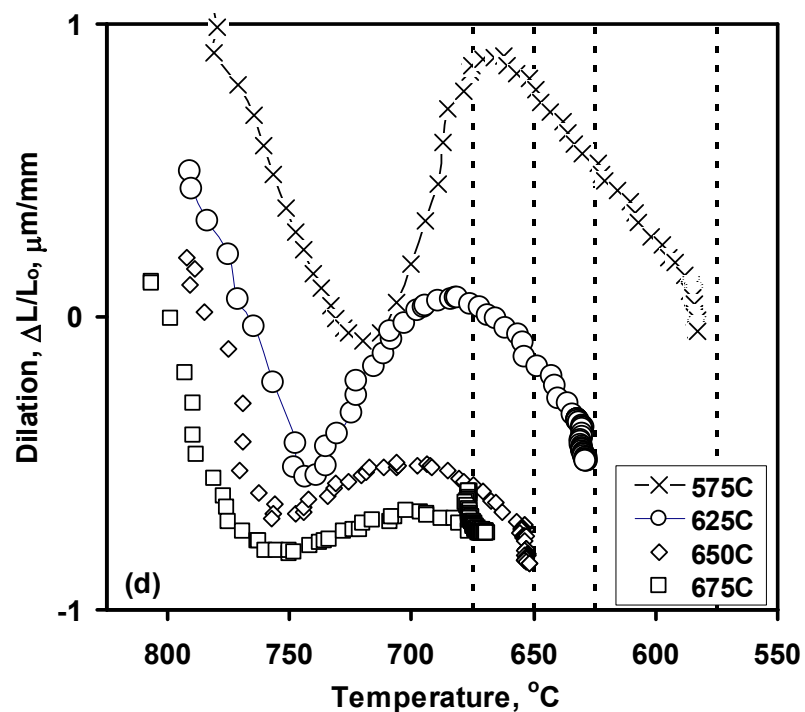

Figure 6. Influence of [N] on dilation of low $\mathrm{C}$ steels under simulated ROT cooling of $2 \mathrm{~mm}$ strip. Plots (a) and (c) are high [N]. Plots (b) and (d) are low [N]. Dashed line: coiling temperature. Open symbols: contraction during coiling. Closed symbols: expansion during coiling. 

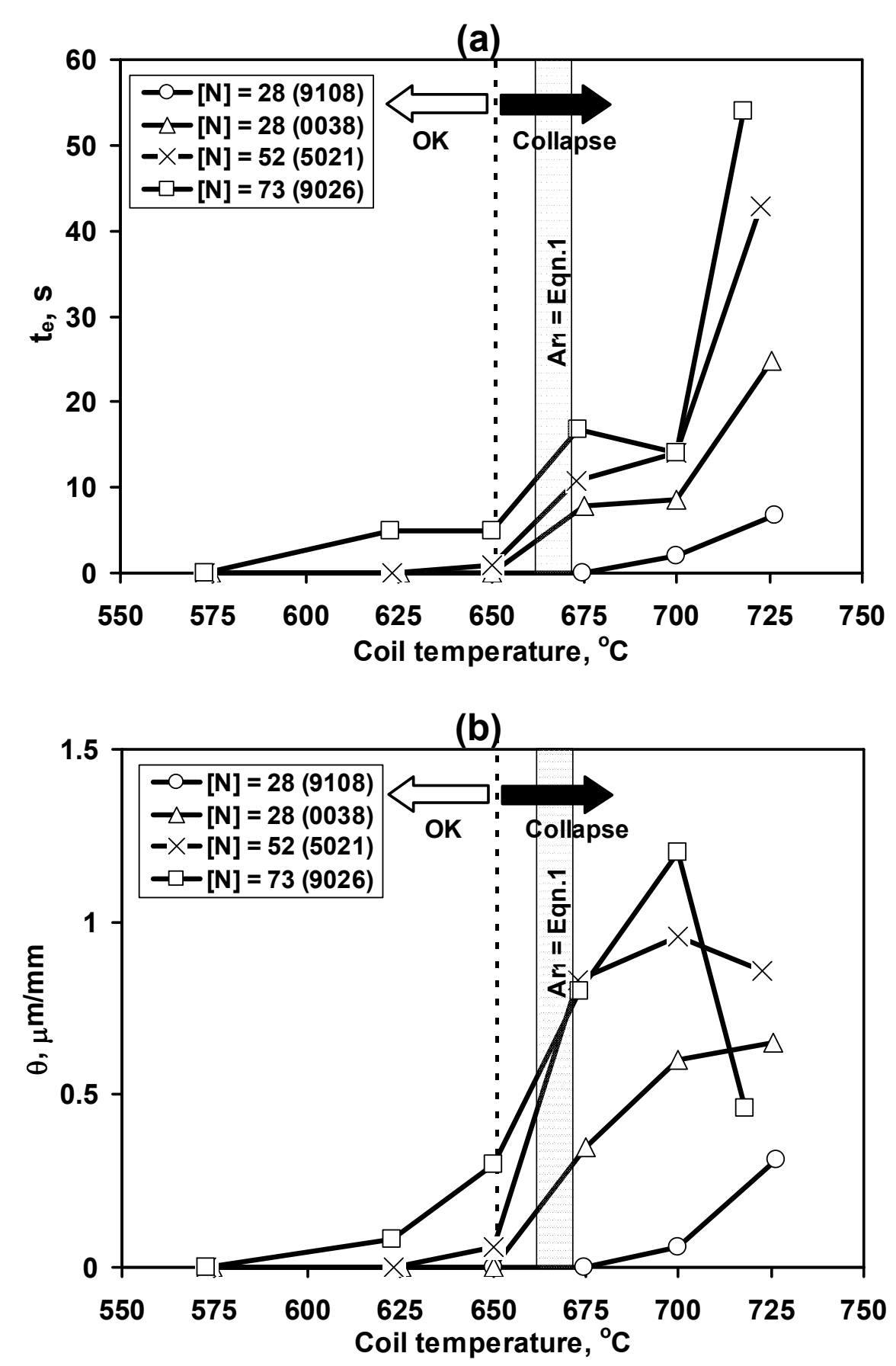

Figure 7. Grade Al steels: Influence of simulated coiling temperature, [N] and C on (a) time to the end of transformation from coiling start, $t_{\mathrm{e}}$ and $(\mathrm{b})$ the maximum dilation. $\mathrm{Ar}_{1}$ calculated from eqn.1. Conventional ROT cooling of $2 \mathrm{~mm}$ strip. Soak $1200^{\circ} \mathrm{C}$.

In all tests the $\mathrm{Ar}_{1}$ temperature calculated from equation 1 generally overestimated the transformation-end temperature, since $t_{\mathrm{e}}$ was greater than zero. The exception was steel 9108, which had low $\mathrm{C}$ and low $[\mathrm{N}]$. This is further evidence that $\mathrm{N}$ lowers the transformation-end temperature 
and should be included as a parameter when calculating $\mathrm{Ar}_{1}$. Thus, from fig.7, it appears that $t_{\mathrm{e}}$ gives a clearer, more consistent indication of collapse than $\theta$, since full dilation can occur in a very short time and the tension can still be corrected. The findings in fig.7 are consistent with the industrial results in fig.2.

Thus, increasing the $\mathrm{N}$ content lowers the transformation temperature region, particularly the $\mathrm{Ar}_{1}$, so that coils containing higher $\mathrm{N}$ levels may not have fully transformed on the runout table and transformation could take place during coiling and subsequent cooling. The dilation observed during the last stages of transformation is attributed to the latent heat of transformation [4] of mostly pearlite, which is the last to transform in these steels under ROT cooling conditions. This observation coincides with an industrially observed rise in coil temperature when transformation is still in progress during coiling. Of course, this temperature rise is not observed in laboratory simulation since the test temperature is controlled and forced to remain isothermal in the coiling stage. Generally, to help prevent coil collapse due to transformation, the targeted coil temperature should be either below $\mathrm{Ar}_{1}$ or comfortably higher than $\mathrm{Ar}_{3}$ for the relevant $\mathrm{ROT}$ system.

$\underline{\mathrm{C}=0.10-0.16 \%}$

Similar trends to those found in low $\mathrm{C}$ steels between $t_{\mathrm{e}}, \theta$ and coiling temperature were found in higher carbon steels B,C and D, fig. 8 . The $\operatorname{Ar}_{1}$ calculated from equation 1 coincided with $t_{\mathrm{e}}$ being early in the coil, 0-20s in all three steels. High incidence of coil collapse corresponded to coiling temperatures above $\mathrm{Ar}_{1}$, and when $t_{\mathrm{e}}$ was greater than $20 \mathrm{~s}$, indicated by the broken lines in the figure. Little or no collapses occurred at coiling temperatures between the solid vertical lines, which corresponded to $t_{\mathrm{e}}$ less than $20 \mathrm{~s}$.

\section{$\underline{\text { Summary and commercial implications: }}$}

It is clear from this work that if transformation is complete before coiling then there should be no problems with coils collapsing. Hence, the $\mathrm{Ar}_{1}$ temperature is very important in dictating the coiling temperature that should be aimed for. For simple C-Mn-Al steels, the $\mathrm{Ar}_{1}$ calculated from equation 1 can be used taking into account that the experimental work indicates that for these coiling conditions it is $\sim 25^{\circ} \mathrm{C}$ too high. When transformation occurs during coiling then there is a need to have as short a time as possible for transformation to complete so that there is time to adjust the coil tension for the dilation. Dilatometry is therefore required to establish whether a particular composition and coiling temperature will lead to coil collapse. 

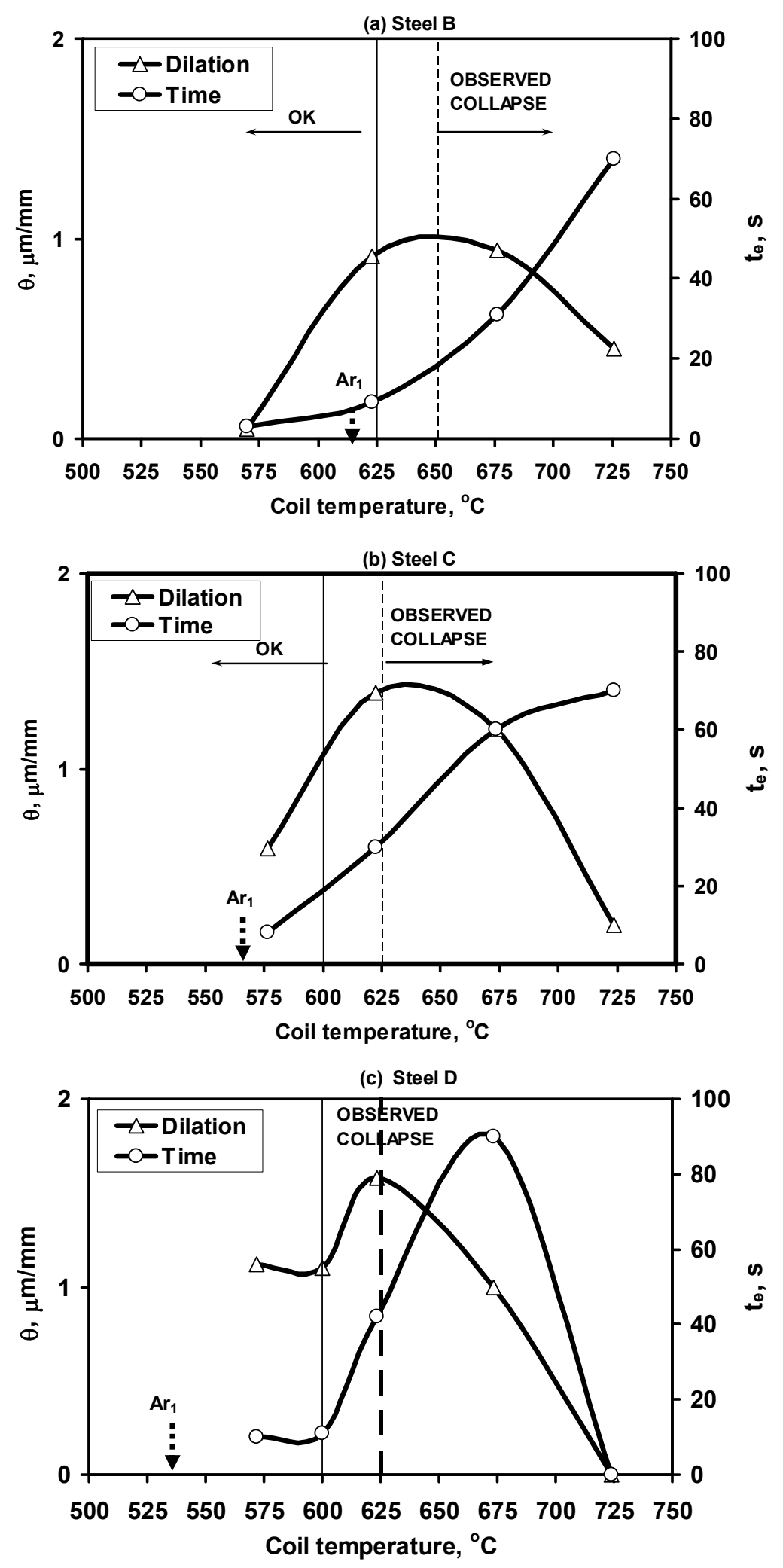

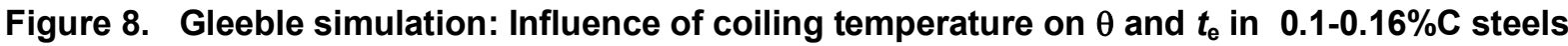
under simulated conventional ROT cooling conditions for $2 \mathrm{~mm}$ strip.

Soak $=1200^{\circ} \mathrm{C} . \mathrm{Ar}_{1}$ calculated from eqn. 1 . 


\section{Conclusions}

1. Industrial data has shown that, in low $\mathrm{C}$ steels, coil collapse is more significant as the nitrogen content increases and coiling temperature increases above $650^{\circ} \mathrm{C}$ due to transformation occurring during the coiling process.

2. Lower $\mathrm{Ar}_{1}$ temperatures increase the likelihood of coil collapse. Whilst lower $\mathrm{C}$ and $\mathrm{Mn}$ contents decrease $\mathrm{Ar}_{1}$, this work has shown that higher $\mathrm{N}$ levels are also detrimental to coil collapse due to further lowering the temperature for the end of transformation. Thus, steels produced at electric arc furnace are more likely to result in coil collapse if corrective action is not taken.

3. A laboratory method has been established that successfully correlates transformation behaviour during simulated runout table cooling and coiling with coil collapse.

4. Laboratory processing conditions resulting in long times to complete transformation, especially associated with large dilation, corresponded to industrial cooling conditions associated with frequent coil collapse.

\section{References}

1. J.M. Hudzia F. Ferrauto and P. Gevers, La Revue de Metallurgie, CIT, (1995), pp938-943.

2. W.Y.D.Yuen and M.Cozijnsen, "Optimum Tension Profiles to Prevent Coil Collapses", SEAISI Quarterly, July 2000, vol.29, 50-59.

3. M. Cozijnsen and W.D.Yuen, "Stress distributions in Wound Coils" Proc. $2^{\text {nd }}$ Biennial Australian Engineering Mathematics Conference, 15-17 $7^{\text {th }}$ July, 1996, Australia, pp117-124.

4. Y.Y.Pan, Ph.D. Thesis. National Sun Yat-Sen University. Taiwan. June. 2001.

5. W.C.Leslie, R.L.Rickett, C.L.Dotson and C.S.Walton: Trans.ASM, 1954, 46, 1470-1499.

6. T.Gladman and F.B.Pickering; J.Iron Steel Inst., 1976, 205, 653-664.

7. Nippon Steel Source, R and D team of the Kimitsu Steel Works of Nippon Steel, 2003.

8. W.P.Sun, M.Militzer and J.J.Jonas. Met. Trans. A. Vol. 23A. March 1992. pp821-830.

9. M.Staiger, C. Davies, B. Jessop, P Hodgson and A. Brownrigg. Thermec '97. Ed.T.Chandra, T.Sakai. Min. Met. And Mat. Soc. 1997. 